\title{
PRINCIPALES APORTACIONES DE MARÍA JESÚS RUBIERA MATA A LA HISTORIA DE LA GRANADA NAZARÍ
}

Manuel RIU

Universidad de Barcelona

Dentro de las principales líneas de investigación de María Jesús Rubiera Mata sin duda una de las más constantes ha sido, y afortunadamente es, la historia del reino nazari de Granada, tanto por lo que respecta a los origenes de la dinastía -los Banu Escallola-, los personajes políticos importantes y su relación con el excepcional conjunto palaciego de la Alhambra -como el wazir Ibn al-ŶYayyāb-; y la sociedad, la familia real y la aristocracia de los últimos tiempos del reino.

Los aspectos literarios -sin olvidar las voces femeninas- $y$ en particular el cultivo de la poesía en Granada de los tres siglos nazaríes le deben una singular atención. Veamos, paso a paso, sus principales aportaciones en estos campos.

\section{a) La sociedad y política granadinas}

La sociedad de al-Andalus estaba cohesionada por los vínculos de sangre. La ayuda de los parientes solía ser esencial para la obtención y conservación del poder. De ahí el interés de un estudio, titulado "El vínculo cognático en al-Andalus" y presentado por $\mathrm{M}^{\mathrm{a}}$ Jesús Rubiera al I Congreso de Historia de Andalucta en diciembre de 1976 (Editado en Córdoba, 1978, tomo I, pp. 121-124), que muestra la atención de nuestra investigadora a esta característica de la sociedad granadina en los dos siglos y medio de existencia del reino de los Banū Naṣr, pues 
demuestra la importancia similar en ella de los agnatos y de los cognatos -contraria a la sociedad árabe-beduina-, acompañando la tabla genealógica de la familia reinante y refiriendo los casos concretos de aplicación de la estructura bilateral por los propios Banū Naṣr.

En "Los Banū Escallola, la dinastía granadina que no fue", trabajo publicado en Andalucla Islámica (Textos y estudios II-III, 1981-1982, Granada 1983, pp. 85-94), dedica asimismo un breve estudio monográfico a los Banū Ašqūīla de Arjona que, en pugna con sus parientes los Banū Nașr, se sublevaron, se enfrentaron con los alfaquíes, buscaron apoyo en la corte de Alfonso X y perdieron la ocasión de reinar.

A partir de la Ihața de Ibn al-Jațib -en buena parte inédita-, completa a su vez la biografla de "El arráez Abū Sa'īd Faray b. Ismā'î b. Nașt, gobernador de Málaga y epónimo de la segunda dinastra nasrí de Granada" (Boletín de la Asociación Espanola de Orientalistas IX, Madrid, 1975, pp. 127-133), muerto en Salobreña en 1320.

Estos tres trabajos, pertenecientes a distintas etapas de su quehacer intelectual, corresponden a esta primera línea de investigación que abre perspectivas renovadoras al estudio de las bases del poder en el mundo nazarf.

\section{b) Aspectos culturales}

Trazar en breves palabras la afección de María Jesús Rubiera por el reino de Granada no resulta tarea fácil. Ya en 1966, en la prestigiosa revista Al-Andalus (XXXI, fasc. 1-2, pp. 377-378) publicó una breve nota sobre "El significado del nombre de los Banū Ašqūlūla", ministros de Muhammad II, sugiriendo su derivación de una gramínea: la escanda, "escaiola" o alpiste. Otra nota, ya más extensa, el año siguiente (1967), proponía la identificación de "Tres topónimos de la frontera granadina" (Al-Andalus, XXXII, fasc. 1, pp. 217-220) en Bedmar, Cuadros y Gaciez.

Un artículo minuciosamente anotado, bajo el hilo conductor de la Ihạta de Ibn al-Jațỉ, traza el perfil biográfico de Ibn al-Hakīm de Ronda ${ }^{1}$ que sumó, en tiempo de Muhammad III, los cargos de katib y

1 "El Dū-1-Wizäratayn de Ibn al-Hakīm de Ronda", Al-Andalus XXXIV, fase. 
wazirr, adquiriendo el título de D̄ū l-Wizāratayn en 1303. Con él cambia la política internacional del reino nazari, que le permite tomar Ceuta e intervenir en las relaciones de Castilla y Aragón, con los mariníes, pero le granjea enemigos y provoca el asesinato de Ibn al-Hakīm en su palacio granadino, en 1309. A María Jesús Rubiera le interesa especialmente, de Ibn al-Hakīm, su cultura y actividad literaria, pues aun siendo un poeta mediano, supo rodearse de los mejores poetas y prosistas de su época. María Jesús Rubiera selecciona y traduce las piezas que estima más notables y, como colofón, incluye la extensa qașíla que Ibn Jamīs de Tremecén le dedico, con imágenes de gran belleza.

La propia autora proporcionaba, en 1970, "Datos sobre una 'madrasa' en Málaga anterior a la nasrí de Granada" (Al-Andalus XXXV, fasc. 1, pp. 223-226) obra del suff Abū 'Abd Allāh al-Sāhilī (m. 1353), hijo de un santón de igual nombre. De ambos, padre e hijo, nos proporciona detalles de la primera mitad del siglo XIV, así como de las vicisitudes de la madrasa, centro de cultura superior, erigida junto a la mezquita mayor de Málaga y dotada con esplendidez.

\section{c) La literatura hispano-árabe}

Especial atención merecen en el aspecto cultural, sus cuatro libros sobre literatura hispano-árabe que intentaremos glosar a continuación.

La serie se inicia con la Bibliografia de la literatura hispano-arabe publicada en 1988 por la Universidad de Alicante ( 75 pp.), en la cual señalaba que el estudio de esta importante faceta de la cultura arábigoislámica de la Península Ibérica, carecía de obras básicas de referencia, por lo cual brindaba una recopilación bibliográfica de 613 entradas, que abarca desde las obras generales correspondientes a los distintos géneros en prosa y en verso clasificadas por períodos, desde el siglo VIII al XV. Los especialistas en literatura hispano-árabe y los estudiantes universitarios pueden hallar en él una guía básica e imprescindible.

Le sigue la Introduccio a la literatura hispano-arab publicada en 1989 por la propia Universitat d'Alacant como volumen primero de la

1 (1969), pp. 105-121. 
Colección Xarc al-Andalus y precedida por un prólogo de Rafael Alemany i Ferrer. En sus 117 páginas se incluyen diez capítulos que examinan sistemáticamente los distintos géneros con particular atención a la poesfa (épica, lírica, estrófica) y la prosa (adab, epistolas, prosa rimada "maqama", historia, libros de viajes, cuentos...) y tres índices alfabéticos: de materias literarias, autores y personajes, y de obras, junto con un extenso cuadro cronologico y ambiental.

Se trata de una obra concisa y clara, dedicada explícitamente a los estudiantes universitarios que, previa una advertencia sobre las lenguas de al-Andalus, introduce al lector en la poesía épica y va desgranando y valorando los distintos temas con un engranaje curioso que ha de servir para fijar la atención del lector. Digamos que es una historia de la literatura acaso atípica por la forma en que está concebida y desarrollada. Y no dudamos que deberá interesar al público universitario al cual va destinada especialmente.

Tercera obra de la serie podemos considerar la Poesía femenina hispanoarabe publicada por Editorial Castalia (Biblioteca de Escritoras) y el Instituto de la Mujer, en Madrid en 1990 (165 pp.). Con esta obra, en la cual se incluye un nutrido florilegio de poesías traducidas, penetramos en el pensamiento y sentimientos de la mujer hispanoárabe. Previa, una amplia introducción sobre la educación de los niños y niñas, la forma de transmisión familiar de estos poemas, su contenido y el papel transmisor de las esclavas cantoras, entre otras muchas consideraciones interesantes. Sigue una bibliografía comentada y la traducción de numerosos poemas a partir de sus lenguas originales (el árabe clásico, el árabe dialectal y un difícil romance), en una amplia antología de veinte poetisas de los siglos VIII al XIV, seguida de otras varias canciones anónimas que se agrupan por temas (requerimiento, queja, confidencia, ausencia...). No mucho después de la publicación de este libro, participaba $\mathrm{M}^{\mathrm{a}}$ Jesús Rubiera en la obra colectiva $L a$ voz del silencio editada por Cristina Segura en la Colección Laya de la Asociación Cultural al-Mudayna (Madrid 1992, pp. 65-69) con un estudio titulado "La voz de las poetisas en al-Andalus y la problemática de la voz femenina literaria medieval" recogiendo, a través de las "moaxajas" y las "jarchas", el sentimiento femenino de forma inusual y atrevida. 
Esta serie culmina con el cuarto libro titulado: Literatura hispanoarabe y publicado en 1992 en la Colección al-Andalus de Editorial Mapfre (283 pp.). Versión muy ampliada del segundo libro que comentábamos, de hecho constituye una obra nueva, tanto por la lengua, como por el desarrollo temático, aunque su esquema le sirva de cañamazo. Es éste un manual universitario que acredita profundidad de conocimientos de la materia y ofrece, con su cronología, bibliografia comentada y actualizada, e índices alfabéticos de personas, nombres técnicos y títulos de obras, cuantos elementos auxiliares pueda necesitar el estudiante de arabismo para comprender la materia. Aquí, además, se intercalan fragmentos significativos de las obras, traducidos al español.

\section{d) La poesía epigráfica}

María Jesús Rubiera descubrió hace ya bastantes años, cuando en torno de 1970 elaboraba su tesis doctoral -leída en la Universidad Complutense de Madrid en 1972-, que la figura de Ibn al-Ŷayyāb, secretario y canciller de la corte nazari, era el autor de parte de los versos epigrafiados en los muros de la Alhambra. Su singular hallazgo lo dio a conocer a la erudición en tres artículos publicados en la revista Al-Andalus de 1970 a 1977 , con sucesivas precisiones.

$\mathrm{Y}$ desde entonces los poemas epigráficos de la Alhambra han continuado despertando su interés. Pero, vayàmos por partes. Al tema dedica primero, como hemos apuntado, tres artículos en la revista $\mathrm{Al}$ Andalus. El primero, titulado "Los poemas epigráficos de Ibn al-Ŷayyāb en la Alhambra" (XXXV, fasc. 2, 1970, pp. 453-473, con 11 fotos) ya constituye un planteamiento general de los problemas que le ha sugerido esta literatura epigráfica, demostrando que Ibn Zamrak no fue el autor de todos los poemas de la Alhambra, como él dijo. Planteamiento que la propia autora irá ampliando con el tiempo en sucesivos trabajos, como veremos. Pero ya señala que Ibn al-Ŷayyāb (m. 1349), Ibn alJațib (m. 1375) e Ibn Zamrak (m. 1390), sucesivamente, ilustraron con sus textos los muros del palacio. En este estudio, $M^{a}$ Jesús Rubiera analiza el estilo, muy semejante en los tres, por pertenecer a una misma escuela, transcribe el texto árabe (con correcciones a las lecturas precedentes) y traduce al castellano los poemas, breves composiciones 
dedicadas a celebrar las construcciones de los emires que han de contribuir a su honra.

Si los textos que redactó Ibn al-Jaṭỉb se han perdido, los del Diwãn de Ibn al-Ŷayyāb recogido por su discípulo Ibn al-Jațīb, podemos releerlos en la Torre de la Cautiva y en las hornacinas del pótico norte del Generalife, permitiendo completar los fragmentos perdidos.

También compuso Ibn al-Ŷyayāb, según la autora, otros poemas epigráficos y los epitafios de las tumbas de varios emires, entre ellos Muhammad II y Muhammad III. Para éste se transcribe y traduce el texto inédito recogido en el Dowan, comparándolo con el de la lápida hallada en Torrijos.

En "De nuevo sobre los poemas epigráficos de la Alhambra" ( $\mathrm{Al}$ Andalus, XLI, fasc. 1, 1976, pp. 207-211, con 2 láminas) demostraba, con base en el Dowán de Ibn al-Jațib, que éste fue el autor de los poemas epigráficos que encuadran los arcos situados a la derecha y la izquierda de la entrada del Salón de Comares, y podía así perfeccionar su lectura e interpretación, proporcionando los textos árabes de las inscripciones, su trađucción y su reproducción fotográfica.

Al tercero de los poetas epigráficos "Ibn Zamrak, su biógrafo Ibn al-Ahmar y los poemas epigráficos de la Alhambra" dedicaba otro estudio en 1977 María Jesús Rubiera (Al-Andalus, XLIII, fasc. 2, pp. 447-451), situando en sus justos límites al poeta, autor de los versos que figuran en los edificios construidos por Muhammad V en la Alhambra, tales como la Sala de las Dos Hermanas, o el Mirador de Lindaraja, pero no de los anteriores, según revela un nuevo manuscrito tunecino de Ibn al-Aḥmar, a quien identifica con Yūsuf III.

Cuatro años después, en 1981, Maŕa Jesús Rubiera en "Poesía epigráfica en La Alhambra y el Generalife" (Poesta, Madrid, núm. 12 (1981), pp. 17-76) recopila el conjunto de textos árabes escritos en paredes y fuentes de los palacios granadinos del siglo XIV, y realiza una cuidadosa traducción de los mismos, acompañada de ilustraciones.

Por último, en 1992, una versión vulgarizadora de "La poesía epigráfica de los palacios de la Alhambra" (Realidad y simbolo de Granada, Banco Bilbao-Vizcaya, pp. 265-271 y 352) resalta el efecto estético y emblemático, a la vez que resume los rasgos biográficos de los tres poetas mencionados. 


\section{e) El estudio esencial sobre Ibn al-Ŷayyāh}

Recientemente, en 1994, $\mathbf{M}^{\text {a }}$ Jesús Rubiera Mata ha vuelto a publicar el estudio de $1 b n$ al-Ŷyyabb. El otro poeta de la Alhambra ${ }^{2}$, adaptación de su tesis doctoral que habra visto ya la luz en 1982, precedida de un enjundioso prólogo de Emilio García Gómez en el cual el maestro prologuista refleja su alegría por haber encontrado en la autora una continuidad anhelada a su labor personal. El poeta granadino Abū-l-Hasan 'Alī b. Muhammad al-Anșārí (1274-1349), más conocido por Ibn al-Ŷayyāb, fue un alto funcionario que hizo rápida carrera al servicio de los sultanes nazaríes, servicio al que ingresó muy joven, y supo, durante más de cincuenta años, conservar con singular habilidad cargos en la corte desde los reinados de Muhammad III hasta Yūsuf I, y su integridad física en los momentos más críticos.

Compilador de un comedido Diwãn cuyo texto árabe en buena parte se reproduce en apéndice (pp. 217-259) con los índices correspondientes, muestra cierto misticismo, pero tanto la autora como el prologuista le regatean originalidad y calidad al compararlo con el asimismo poeta de la Alhambra, Ibn Zamrak.

Casi cuanto sobre Ibn al-Ŷayyāb sabemos se lo debemos al polígrafo Ibn al-Jațīb, su discípulo y recopilador de los poemas, conservados no sólo en el manuscrito de la Biblioteca Nacional de El Cairo, sino también caligrafiados en las paredes del Partal de la Alhambra, de la Torre de la Cautiva, asimismo de la Alhambra, y de las dos tacas del Pórtico Norte del palacio de verano del Generalife. Esta poesía epigráfica, muy decorativa, se halla reproducida en catorce fotografías en color, de una gran claridad, en las páginas del libro.

El estudio y edición de 1994 cierra, por ahora, un amplio ciclo abierto hace unos veinticinco años por $M^{a}$ Jesús Rubiera, de la mano de Elías Terés. Es una obra minuciosamente anotada, muy bien escrita y editada con no menor cuidado, que acredita el buen hacer editorial del Patronato de la Alhambra y el Generalife, bajo el patrocinio de la Consejería de Cultura y Medio Ambiente de la Junta de Andalucia.

${ }^{2}$ Patronato de la Alhambra y Generalife, Granada, '1982, 187 pp.; ${ }^{2} 1994$, 259 pp., 14 láms. 
Las fuentes biográficas, manuscritos y copias, abren el volumen. Se examina, a continuación, la vida de Ibn al-Ŷyayyāb, empezando por sus estudios de las ciencias religiosas y profanas, con los maestros Ibn al-Zubayr y Abū l-Hasan, que le convertirían en conspicuo alfaquí y místico a la moda de su tiempo, y en funcionario destacado desde muy joven del Diwān al-Insă' nazarí bajo sucesivos sultanes.

Ibn al-Ŷayyāb (1274-1349), Ibn al-Jațīb (1313-1375) y Ibn Zamrak (1333-1393) fueron, pues, los tres autores sucesivos de los poemas epigráficos de la Alhambra, como altos funcionarios-poetas de la corte. Las casidas que dedican a los sultanes, referidas a acontecimientos de la corte, cabe considerarlas un precedente de las crónicas periodísticas de un servicio de prensa actual. Salvo que en la Granada nazarí, como antes en otros reinos de la España islámica, estos narradores eran poetas que habían aprendido la difícil técnica de la versificación para elogiar a sus patrocinadores y silenciar sus derrotas. Gracias a ellos conocemos, no obstante, la versión oficial -naturalmente encomiástica- de los hechos importantes y de los personajes que intervenían en los mismos: fiestas, pascuas y batallas, no menos que bodas y nacimientos de príncipes, $o$ elogios fúnebres.

Con un perfecto conocimiento de las fuentes, va desgranando la doctora Rubiera la vida de Ibn al-Ŷayyāb; su misticismo se expresa en un poema (pp. 60-61), en el cual se elogian las virtudes del vino puro y sus efectos, lleno de símbolos lumínicos en el camino hacia el conocimiento de la Divinidad. Mahoma es invocado con frecuencia como el camino de salvación hacia Allāh. Aparece Ibn al-Ŷyyyāb como hombre honrado y piadoso.

Poco se sabe de su familia y sus hijos, a la muerte del mayor de los cuales dedicó unos sentidos trenos, transido de dolor (pp. 64-67), que expresa mediante símbolos tales como el mar desbordado de dolor, la lengua enmudecida y el engaño de la resignación. Junto a ellos, detalles valiosos para el arqueólogo, como cuando dice que lo depositó en la tumba "apoyado sobre su lado derecho" y que colocó encima la correspondiente lápida. Ibn al-Jațib fue su hijo espiritual y discípulo predilecto.

María Jesús Rubiera, después de glosar en Ibn al-Ŷyyyāb "al puntilloso funcionario, al hábil cortesano, al fervoroso místico, al padre amantísimo y al generoso maestro" (p. 70), llama la atención sobre un 
último aspecto de su carácter, su humorismo, su afición a las bromas $\mathrm{y}$ adivinanzas.

La muerte de Ibn al-Ŷayyāb ocurre en Granada, en enero de 1349 , en plena Peste Negra, aunque al parecer no muriera de ella, cumplidos los setenta y cinco años. Ibn al-Jaṭib le dedicó un extenso poema (pp. 72-75), en que glosa su honradez, su finura intelectual, su afabilidad e indulgencia, su espíritu conciliador.

La obra poética de Ibn al-Ŷayyãb ocupa la segunda parte del volumen, minuciosamente estudiada por temas: a) poesía de tema religioso, con examen de sus peculiaridades métricas que quedan explicitadas en un hermoso ejemplo (pp. 80-82) que -no obstante los "terribles ripios"- incita al pecador a acudir al Profeta para que interceda por él ante Dios. b) Poesía panegírica: las 57 casidas dedicadas a los sultanes, a elogiar su persona, su carácter, sus hechos, sus virtudes; a ensalzar sus festejos, pascuas musulmanas, batallas, construcciones de palacios, bodas y nacimientos... y los epitafios en las lápidas de sus tumbas. c) Poemas de amistad: súplicas, reproches, felicitaciones... d) Adivinanzas y poemas variados, expresión de su ingenio. e) Poemas epigráficos que encuadran las hornacinas o tacas del Pórtico Norte del Generalife y que se hallan asimismo en otros lugares y piezas, como en muebles, tejidos, un jarrón de la época de Ismā'îl I, o los ángulos de la Torre de la Cautiva.

Le sigue un estudio de la época que le tocó vivir a Ibn al-Ŷayyāb -la primera mitad del siglo XIV-a través de su obra y en torno de los sucesivos emires. Destaca: un odio feroz al enemigo cristiano, elogios a los emires, la brillantez de Granada y la Alhambra. Abundan las traducciones intercaladas, por reinados, con detalles valiosos como las referencias a los palacios, los paseos entre jardines y surtidores, las carreras de caballos, etc. Los días de paz y de placer alternan con los días de guerra.

A señalar, asimismo, dos apéndices: 1) Ibn al-Jațīb y sus poemas en las hornacinas de la entrada del Salón de Comares. 2) Ibn Zamrak, su biógrafo Ibn al-Jațib y los poemas epigráficos de la Alhambra. Sigue un minucioso índice analítico de todos los poemas del Diwān, en el cual se indica los que se editan a continuación en el volumen. Se incluyen también sendos índices alfabéticos de nombres de personas y de lugares. 
Y cierra el volumen la edición selectiva (pp. 217-259) del texto árabe del Diwan.

\section{f) Otros temas culturales}

Los temas relacionados con la cultura islámica, y en particular con la poesía, han apasionado -y apasionan sin duda- a María Jesús Rubiera. De ello nos ha proporcionado otras abundantes muestras. Desde "Las décimas del profeta" ${ }^{\text {"3 }}$, en que analiza este tipo de poemas, casidas de diez versos que pueden alcanzar a tener veinte o treinta o sólo cinco en la Granada nazarí, y presentan una figura retórica -epanadiplosis- que repite al final la palabra con que comenzó. Dedicadas a la alabanza de Mahoma y otros temas místicos, estas poesías de origen culto, con técnica propia, resultan complejas y desde el siglo XIII se convierten en un género de moda. Entre sus cultivadores destaca el granadino Ibn al$\hat{Y}$ ayyāb a quien la doctora Rubiera ha dedicado tantas páginas. También las ha dedicado, asimismo, a Sa 'îd ibn Hakam (m. 1251), señor de Menorca, natural de Tavira en el Algarbe y residente primero en Sevilla, que convirtió su corte insular en centro cultural en la primera mitad del siglo XIII, edificando un palacio de recreo junto a Ciudadela. En esta corte vivieron el poeta sevillano Ibn Sahl e Ibn Yāmin de Alcira, con los que intercambió su señor bellos poemas ${ }^{4}$.

A partir de la poesía desarrolla María Jesús Rubiera nuevos temas, tales como el "arquitectónico", en La arquitectura en la literatura árabe. Datos para una estética del placer (Editora Nacional, Madrid, 1981, 178 pp. Nueva edición con textos complementarios, Ed. Hiperión, Madrid, 1988), donde numerosos textos literarios en prosa y en verso sobre descripciones de ciudades, palacios, jardines, baños y mezquitas son puestos a colación para observar la mezcla inextricable de fantasía y realidad en la mentalidad e imaginación árabes. También en los "Arquetipos ideales de la ciudad árabe" (ponencia del Congreso

3 "Las décimas del Profeta (Mu'aššarāt, 'Išrinniyyāt, talātiniyyāt y mujammasāt: versos con epanadiplosis en la poesía hispano-árabe", $A$ l-Qantara, Madrid, I (1980), pp. 55-64.

4 "La corte literaria de Sa'id de Menorca (s. XIII)", Revista de Menorca, Mahón, LXXV (1984), pp. 105-138. 
dedicado a La Ciudad Islámica, Zaragoza, 1991, pp. 57-64), glosa la estética de la ciudad arquetipica, idealizada, a través del relato de Abū Hāmid el Granadino, y la influencia en las ciudades de al-Andalus, principalmente Valencia. Otro tema, desarrollado a partir de la poesfa, es "La descripción poética de los palacios árabes: datos para la definición del género 'qușūriyyāt'" (pp. 213-215). En los tres casos se advierte el valor de la poesía como fuente histórica, mediante sus descripciones idealizadas.

También insistiría, mientras tanto, en las características de los dialectos arábigo-granadino y arábigo-valencianos, en ocasión del comentario de dos tesis doctorales.

En la actualidad María Jesús Rubiera continúa prestando atención al reino nazarr de Granada y a las consecuencias inmediatas de su destrucción, tales como la figura de Boabdil y la familia real granadina, o a las grandes familias que se convirtieron al cristianismo a raiz de la conquista del reino por los Reyes Católicos.

5 "Precisiones sobre los dialectos arábigo-granadino y arábigo-valenciano", Sharq Al-Andalus. Estudios árabes, Alicante, 1 (1984), pp, 151-152. 